\title{
Poetry Between, Among, and in the Midst
}

by Denise Newman

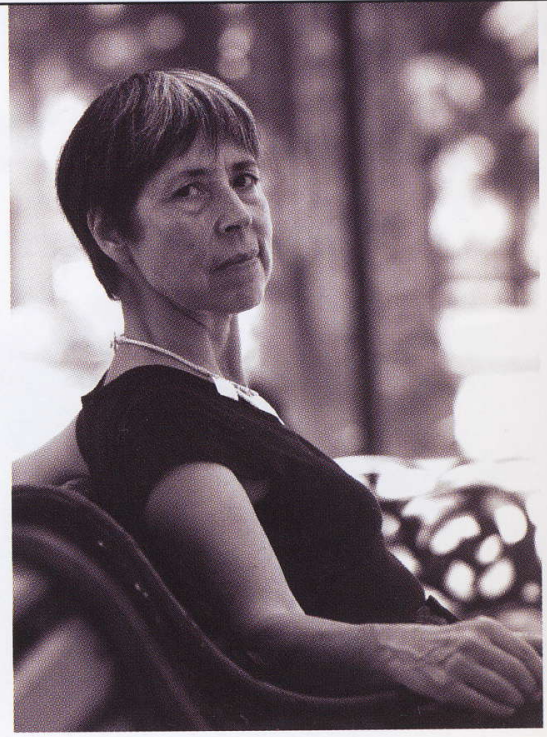

CECILIA VICUÑA

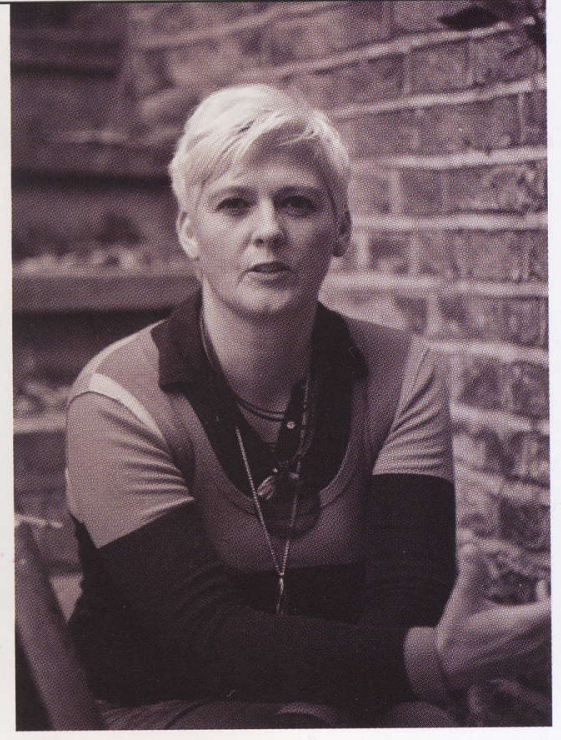

CAROLINE BERGVALL
EARLIER INNOVATIONS in poetry, such as futurism, dadaism, and concrete poetry, were interdisciplinary and international-containing the prefix inter-, meaning between, among, in the midst. Kurt Schwitters (1887-1948), for example, worked between the disciplines of fine art, poetry, performance, and graphic art. Scraps of debris and scraps of words and sounds were equally useful in his investigations, and one of his most enduring works, Ursonate, is both a sound poem as well as a graphic score. Everything Schwitters made he called "Merz," a term coined to encompass his multifaceted undertaking of "establishing relationships," as he said, "between all the things in the world."

Increasingly, poets today are working across disciplines, often spanning two or more cultures. Cecilia Vicuña, who as a young artist in Chile was inspired by an image of Schwitters's Merzbau, continues his it's-all-material and it's-all-connected spirit, forging her own path "between" and "among." Forced to leave Chile in the early 1970s during the coup, she now divides her time between New York City and Santiago and maintains a deep connection to the indigenous culture of the Andes, and has adapted the ancient Incan form of communication called quipu that uses knots in wool strings as an aid to memory. Visual

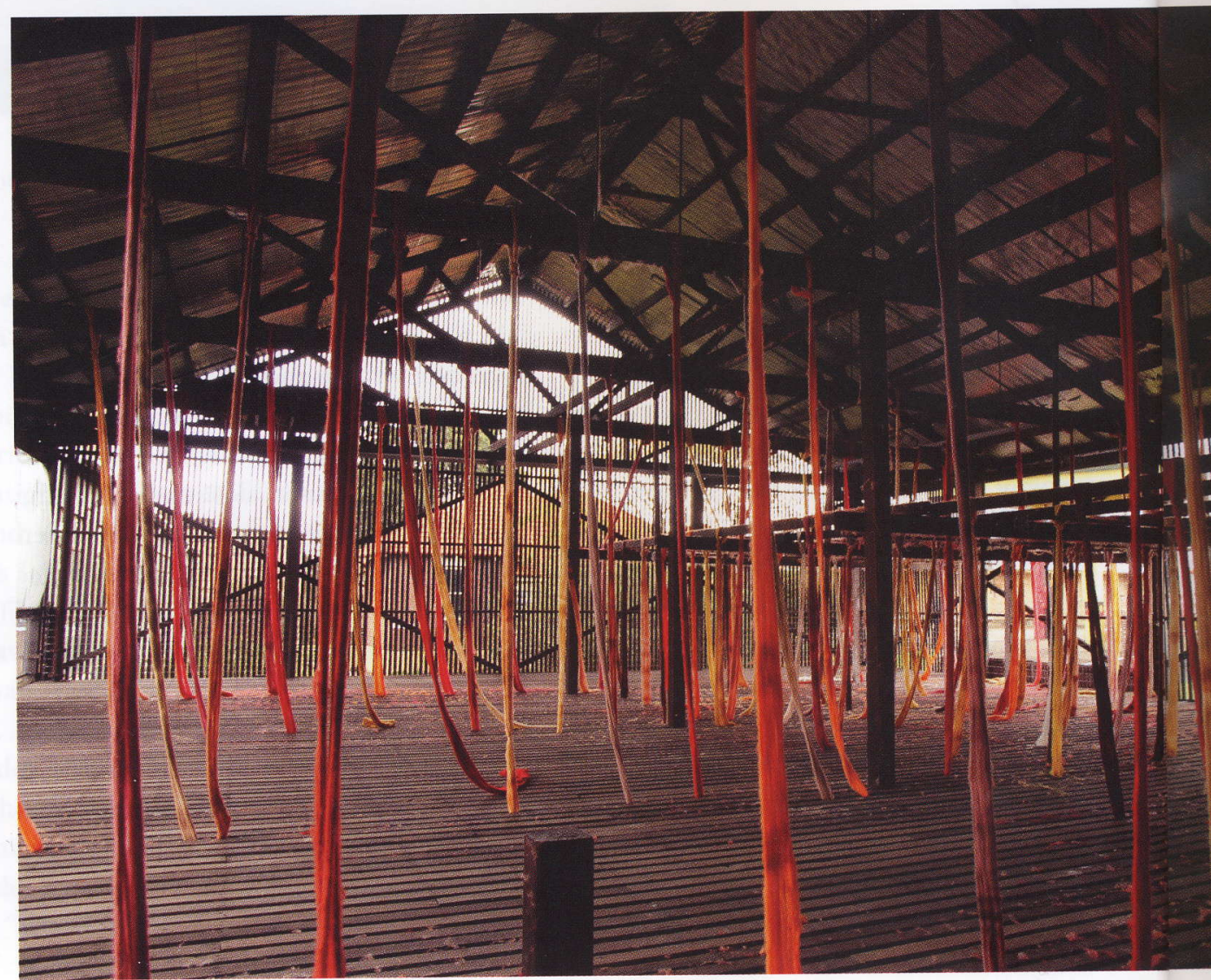

ABove Cecilia Vicuña's 2012

installation, Quipu Austral, at the 18th Sydney Biennale, Cockatoo Island. 

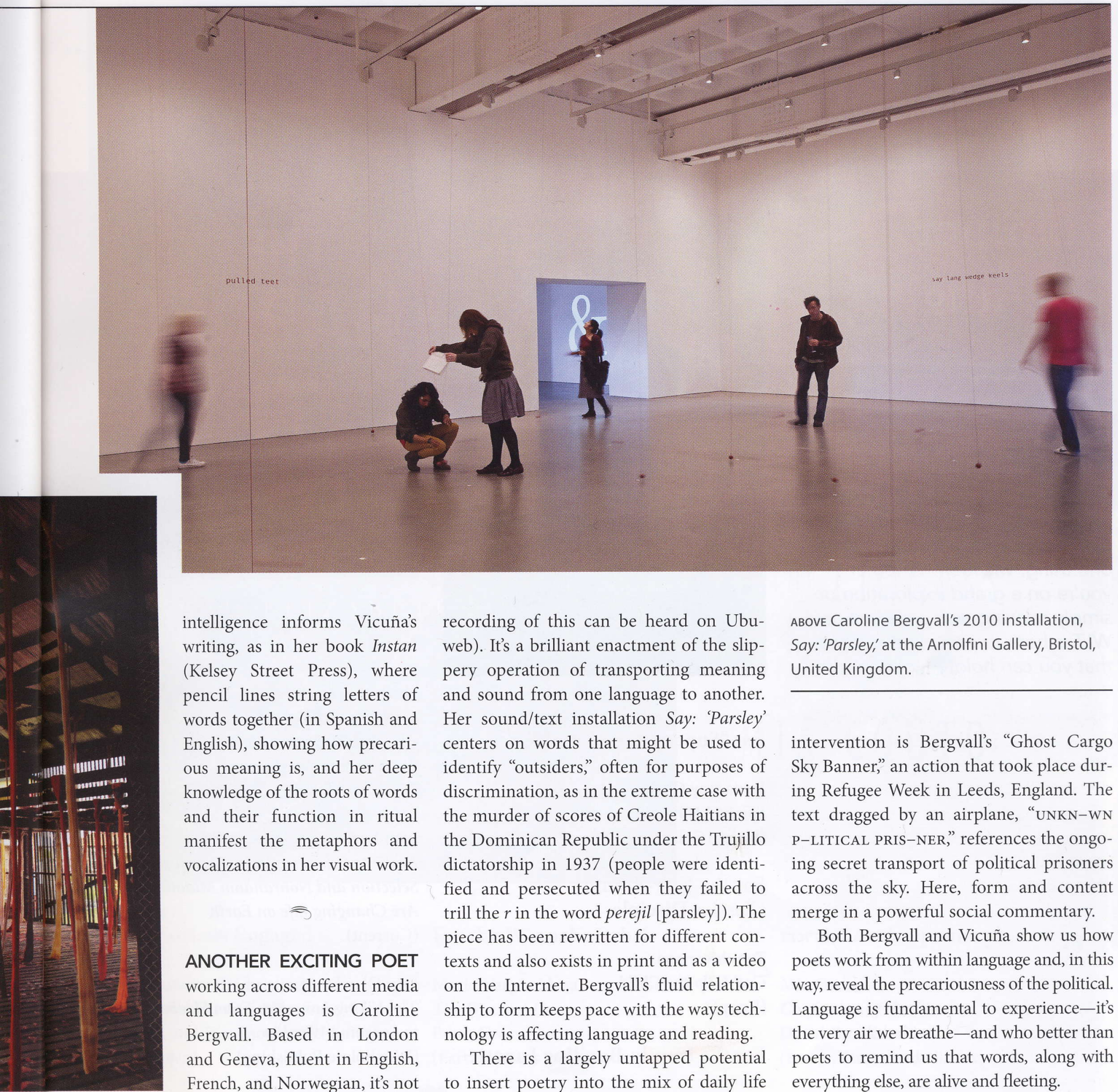

intelligence informs Vicuña's writing, as in her book Instan (Kelsey Street Press), where pencil lines string letters of words together (in Spanish and English), showing how precarious meaning is, and her deep knowledge of the roots of words and their function in ritual manifest the metaphors and vocalizations in her visual work.

$$
\approx
$$

\section{ANOTHER EXCITING POET}

working across different media and languages is Caroline Bergvall. Based in London and Geneva, fluent in English, French, and Norwegian, it's not surprising that her works show a heightened awareness of the nuances of pronunciation, mishearings, and the uncanny spaces between languages. In Via, Bergvall reads forty-eight English translations, made between 1805 and 2000, of the first three lines of Dante's Inferno (a recording of this can be heard on Ubuweb). It's a brilliant enactment of the slippery operation of transporting meaning and sound from one language to another. Her sound/text installation Say: 'Parsley' centers on words that might be used to identify "outsiders," often for purposes of discrimination, as in the extreme case with the murder of scores of Creole Haitians in the Dominican Republic under the Trujillo dictatorship in 1937 (people were identified and persecuted when they failed to trill the $r$ in the word perejil [parsley]). The piece has been rewritten for different contexts and also exists in print and as a video on the Internet. Bergvall's fluid relationship to form keeps pace with the ways technology is affecting language and reading.

There is a largely untapped potential to insert poetry into the mix of daily life in myriad forms and places. Visual artists such as Jenny Holzer and Lawrence Weiner have been enlivening civic spaces with language for decades, whereas poets, if anyone thinks to include their words, are usually given bronze plaques embedded in sidewalks. One bold example of a poet's
ABOVE Caroline Bergvall's 2010 installation, Say: 'Parsley,' at the Arnolfini Gallery, Bristol, United Kingdom.

intervention is Bergvall's "Ghost Cargo Sky Banner," an action that took place during Refugee Week in Leeds, England. The text dragged by an airplane, "UNKN-WN P-LITICAL PRIS-NER," references the ongoing secret transport of political prisoners across the sky. Here, form and content merge in a powerful social commentary.

Both Bergvall and Vicuña show us how poets work from within language and, in this way, reveal the precariousness of the political. Language is fundamental to experience-it's the very air we breathe - and who better than poets to remind us that words, along with everything else, are alive and fleeting.

Denise Newman is a translator and a poet who has published three collections of poetry. She has translated two books by Denmark's greatest modernist author, Inger Christensen, and, most recently, Naja Marie Aidt's short-fiction collection, Baboon. 